University of Wollongong

Research Online

Faculty of Social Sciences - Papers (Archive) Faculty of Arts, Social Sciences \& Humanities

January 2016

\title{
The benefits and challenges of girl-focused Indigenous SDP programs in Australia and Canada
}

Lyndsay M C Hayhurst

Brock University

Audrey R. Giles

University of Ottawa

Jan Wright

University of Wollongong, jwright@uow.edu.au

Follow this and additional works at: https://ro.uow.edu.au/sspapers

Research Online is the open access institutional repository for the University of Wollongong. For further information contact the UOW Library: research-pubs@uow.edu.au 


\title{
The benefits and challenges of girl-focused Indigenous SDP programs in Australia and Canada
}

\author{
Abstract \\ In this chapter, we examine the impact of sport for development and peace (SDP) initiatives for girls in \\ two different contexts: Canada and Australia. While Canada and Australia share a mutual heritage on a \\ number of fronts, for the purposes of this chapter, perhaps one of the most profound parallels between \\ these two countries is a shared colonial history, with government by white settler societies and cultures \\ resulting in extensive exploitation and dispossession of Indigenous traditional land. Also, despite \\ important differences, in both countries, racist legislation (i.e., the Indian Act in Canada in 1876, the \\ Aboriginal Protection Act in Australia in 1869) contributed to great harms to Indigenous peoples, and neo- \\ colonial and neoliberal forms of domination and oppression have continued to subjugate and negatively \\ impact the lives of Indigenous peoples. This has not been without resistance, such as through struggles \\ for land rights and other activist movements such as "Idle No More" (INM), which focuses on promoting \\ Indigenous knowledge and is anchored in Indigenous self-determination, calling on all people to "join in a \\ peaceful revolution, to honour Indigenous sovereignty, and to protect the land and water" (INM n.d., para. \\ 1).

\section{Keywords} \\ canada, focused, girl, challenges, benefits, programs, sdp, australia, indigenous

\section{Publication Details} \\ Hayhurst, L. M. C., Giles, A. R. \& Wright, J. (2016). The benefits and challenges of girl-focused Indigenous \\ SDP programs in Australia and Canada. In L. M. C. Hayhurst, T. Kay \& M. Chawansky (Eds.), Beyond Sport \\ for Development and Peace: Transnational perspectives on theory, policy and practice (pp. 111-127). \\ Abingdon, United Kingdom: Routledge.
}


Hayhurst, L., Giles, A. \& Wright, J. (2015) The benefits and challenges of girl-focused Indigenous SDP programs in Australia and Canada, in L. Hayhurst, T. Kay \& M. Chawansky (eds) Beyond Sport for Development and Peace: Transnational perspectives on theory, policy and practice. Routledge

\begin{abstract}
In this chapter we employ a postcolonial feminist perspective informed by girlhood studies to investigate two SDP programs, one in Canada and one in Australia, that focus on urban Indigenous girls. Interviews with program leaders allowed us to identify the benefits and challenges of the programs. The challenges related to intersecting gender inequalities, (neo-)colonialism, and Aboriginal culture. To address these challenges, we argue that SDP programs that target urban Indigenous girls and women need to connect to broader activist agendas to address the structural issues that continue to result in Indigenous girls and young women being deemed as in need of development initiatives. Wendy Lahey reflects on this chapter through her experiences as a non-Indigenous female working as an outdoor leadership consultant for the Northwest Territories Recreation and Parks Association
\end{abstract} (NWTRPA).

\title{
Introduction
}

In this chapter, we examine the impact of sport for development and peace (SDP) initiatives for girls in two different contexts: Canada and Australia. While Canada and Australia share a mutual heritage on a number of fronts, for the purposes of this chapter, perhaps one of the most profound parallels between these two countries is a shared colonial history, with government by white settler societies and cultures resulting in extensive exploitation and dispossession of Indigenous traditional land. Also, despite important differences, in both countries, racist legislations (i.e., the Indian Act in Canada in 1876, the Aboriginal Protection Act in Australia in 1869) contributed to great harms to Indigenous peoples and 
neo-colonial and neoliberal forms of domination and oppression have continued to subjugate and negatively impact the lives of Indigenous peoples. This has not been without resistance, such as through struggles for land rights and other activist movements such as "Idle No More” (INM), which focuses on promoting Indigenous knowledge and is anchored in Indigenous self-determination, calling on all people to "join in a peaceful revolution, to honour Indigenous sovereignty, and to protect the land and water” (INM n.d., para. 1).

These movements highlight the current socio-political climate of Indigeneity in Canada, Australia, and in other white settler societies where there are ongoing concerns about Indigenous rights to land, education, health, economic development and, ultimately, self-determination. In this context, Indigenous young women and girls are amongst the most disadvantaged groups, with extreme disparities in health status between female Indigenous and non-Indigenous populations in Australia and Canada (McHugh, Coppola \& Sinclair 2013; Nelson 2009; Nelson, MacDonald \& Abbott 2010). What is particularly relevant to this chapter is the difference between young Indigenous women's participation in sport and physical activity compared to their male counterparts (Giles 2004; Rynne \& Rossi 2012). In an attempt to address these issues, sport and recreation programs in Australia and Canada have been developed to utilize sport as a catalyst to achieve social development, healthy living, and educational objectives with Indigenous youth populations (e.g., see Right To Play 2014). The use of sport as a tool to address social, economic, and environmental disparities is part of a growing movement - the subject of this edited collection - known as SDP (Kidd 2008).

The increase in, and 'need for', SDP in Indigenous communities in countries like Australia and Canada has been explained as a response to the withdrawal of the welfare state and the increasingly neoliberal character of social services provision in both Canada and Australia (e.g., 
Hayhurst \& Giles 2013; Rossi \& Rynne 2013), where NGOs and civil society organizations have stepped in to fill the "governance gap” (Coleby \& Giles 2014). Despite the growing number of corporate-sponsored SDP initiatives that target Indigenous peoples (Hayhurst \& Giles 2013) and communities in the Global South World (Hayhurst 2011a, 2011b), scholars have largely ignored how such initiatives impact marginalized groups in the Global North. With some exceptions (e.g., Galipeau \& Giles 2014; Hayhurst et al. 2015; Nelson 2009; Rovito \& Giles 2013; Rynne \& Rossi 2012; Rossi \& Rynne 2013), there are few studies that have focused on the sport and recreation experiences of Indigenous youth (particularly young women and girls) in Canada and Australia, or that have considered how funding impacts the ways that youth take up these programs.

The broader research study on which this chapter is based addressed these gaps in the SDP literature by focusing on two issues: i) the ways Aboriginal girls in Canada and Australia understand and experience participation in SDP programs; and ii) how private sector involvement in sport and recreation provision in Aboriginal communities in Canada impacts SDP programming. In order to pursue these goals, the larger study examined the experiences of Indigenous young women (ages 1635 years), organizational staff members, and corporate funders associated with two recreation and sport programs provided by NGOs in two major urban cities within Australia and Canada; however, in this chapter, we focus exclusively on data produced through interviews with the program managers and staff who administered these initiatives to obtain their perspectives on the benefits and challenges involved in creating and implementing SDP programs for Indigenous young women. Thus, the overarching research question guiding this specific chapter is, "What do NGO staff consider to be the benefits and challenges involved in creating and implementing SDP programs for Indigenous young women and girls in Australia and Canada?’ 'Benefits' here refer to the perceived 'positive' elements of the program, such as improved social support and 'challenges' to the barriers 
staff identified as operating both inside and outside of the programs (i.e., poverty or lack of child care).

\section{Youth, gender, and SDP for urban Indigenous communities in Canada}

While cities can offer Indigenous peoples enhanced opportunities for education, employment, health care, housing, and - especially for those escaping domestic abuse - safety, urban environments are also places where Indigenous peoples experience racism and social exclusion (Place 2012). Vancouver has the third largest Indigenous population of any city in Canada, with 40,310 Indigenous residents comprising $2 \%$ of the city’s total population (Statistics Canada 2008). While some of these residents have spent their entire lives in Vancouver, others have come from smaller Indigenous communities (Environics 2011). Compared to non-Indigenous residents of Vancouver, Indigenous peoples have higher rates of unemployment and lower levels of education and income (Statistics Canada 2008).

The use of sport for development within Indigenous communities in Canada is a rapidly growing area, though one with a complex history due to the use of sport for colonial goals within the residential school system and broader efforts to instill colonial values (Coleby \& Giles 2013). To date, most of the large-scale, well-established programs for Indigenous youth have focused on those who live in rural and remote communities. For example, Alberta's Future Leaders Program sends pairs of (typically) university and college students from urban centres to First Nations reserves and Métis settlements across Alberta to promote summer-time sport, recreation, and leadership development to Indigenous youth. Galipeau and Giles (2014) found that participants in Alberta’s Future Leaders Program felt that the program has the potential to halt or prevent Indigenous youths' negative life trajectories, but also noted that in focusing on the individual, the program does not 
address the broader social issues, like colonialism, that contribute to Indigenous youths' marginalization. While the program now often includes programming at one urban location in any given year, the program delivery model has focused on rural and remote communities (Galipeau \& Giles 2014).

Similarly, Right To Play, an international SDP NGO, has established Promoting Life-Skills in Aboriginal Youth (PLAY) in rural and remote Indigenous communities in northern Ontario. As of 2012, it was operating in 39 northern Ontario communities (Talaga 2012). On its website, Right To Play states that $82 \%$ of participants believed that they were stronger leaders due to their involvement in the PLAY program (Right To Play 2014). Rose and Giles (2007) and Rousell and Giles (2012), however, pointed out that Eurocentric understandings of leadership do not necessary align with Indigenous understandings of leadership, which can cause problems in leadership programming for Indigenous youth. Right To Play is nevertheless expanding its programs to include urban Indigenous communities (Right To Play 2014). Certainly, given the high percentages of Indigenous peoples who live in urban settings within Canada, it is unsurprising that sport for development programs are becoming increasingly popular in these contexts.

\section{Youth, gender and SDP for urban Indigenous communities in Australia}

In Australia, people identifying as Aboriginal and Torres Strait Islander (ATSI) make up 2.5\% of the Australian population. As is the case in Canada, the ATSI population is younger and growing at a faster rate than the non-Indigenous population. In 2006, 38\% of the Indigenous population was under 15 years of age compared with 19\% of the non-Indigenous population (Australian Human Rights Commission 2008). In relation to health and other indicators of disadvantage, young 
Indigenous Australians fair significantly less well when compared with non-Indigenous youth (Killon \& Magnus 2010).

Sport is a complicated space in Indigenous culture and history in Australia. It is the site of racist assumptions of the "natural” Indigenous sporting body, gifted with innate special abilities or a body pathologized as deficient and as failing to be active and healthy (Nelson, MacDonald \& Abbott 2010). Sport is also a site of exploitation and damage, but as well as a way out of disadvantage and a source of community pride and social engagement (Tatz 1994). Because of its significance to Indigenous peoples, sport has been promoted as a useful way of developing partnerships with Indigenous communities to promote health through physical activity.

There are examples in Australia of government run sport development programs in partnership with the Australian Sports Commission. For example, the Western Australian government runs an Aboriginal Sport Program aimed at encouraging ”Aboriginal people to be more active and play sport at all levels"; "learn skills to organize ... community-based sport”; and support talented athletes (Government of WA 2014). Rossi and Rynne (2013) and Rossi, Rynne and Nelson (2013) have explored government-funded programs of sport in Indigenous communities using concepts such as neoliberalism and 'white guilt,' while also expressing their struggles in engaging with decolonizing methodologies; however, besides these studies - and a few other exceptions (e.g., MacDonald, Abbott \& Jenkins 2012) - to date there seem to have been limited attempts, other than those reported in this paper, that specifically use sport as a catalyst for social development, nor any that specifically target girls and young women.

\section{Examining Indigenous, gender-focused SDP through postcolonial feminism and girlhood} studies 
In interpreting the results of the study for this paper, we were guided by postcolonial feminist theory, which pushes researchers to examine the material and symbolic inequalities and struggles of historically situated agents in the global economy (McEwan 2009). Postcolonial feminist approaches also emphasize the ways race, class, gender and (neo-)colonial power relations overlap to create oppressive conditions for disadvantaged groups (Marchand 2009). Along these lines, we engaged with an intersectional approach to attend to the "interaction between gender, race and other categories of difference in individual lives, social practices, institutional arrangements, and cultural ideologies and the outcomes of these interactions in terms of power" (Davis 2008, p. 68). Intersectionality complements postcolonial feminist approaches because, by conceptualizing multiple and shifting identities, it encourages the deconstruction of essentialist positions and binary categories (Davis 2008). Importantly, intersectional approaches can be used to expose inequality and enhance social justice (Cho, Crenshaw \& McCall 2013).

Scholars such as Harris (2004) have suggested that girls in the twenty-first century are powerful and confident individuals who participate in global society; however, such research risks essentializing girls by ignoring the impact of colonization and the intersecting politics of gender, race, and class that interlock to exacerbate the disadvantages experienced by Aboriginal girls in Canada and Australia. To avoid this risk, the research described in this chapter was also steered by postcolonial and Indigenous girlhood studies scholars, such as de Finney (2010). These scholars have advocated for nuanced and complex understandings of girlhoods by foregrounding deep-seated historical, structural and material inequities, and neo-colonial forces that contribute to Indigenous and other racialised girls' "overrepresentation in indicators of social exclusion, including gendered, classed, sexualised, and racialised discrimination and violence” (de Finney 2010, p. 484). 
Taken together, a postcolonial feminist intersectional approach, informed by a girlhood studies perspective, provides a robust theoretical platform to explore the perceived benefits and challenges involved in creating and executing SDP programs that target Indigenous young women and girls. Such a platform provides the means to question unequal material relations of power and the discursive framework within which these relationships have been constructed when exploring the perceived benefits and challenges involved in creating and executing SDP programs that target Indigenous young women and girls.

\section{The Study: A Comparative Approach to Examining SDP-focused Indigenous Programs}

In this chapter we discuss data from two case studies: one in Canada with Vancouver Aboriginal Friendship Centre Society (VAFCS); and the other in Australia with a program run by Role Models and Leaders Australia (RMLA). Below, we provide more context and background on each of these organizations before discussing data generation and analysis.

Vancouver Aboriginal Friendship Centre Society (VAFCS)

VAFCS was established as a non-governmental organization in 1956. It provides Indigenous and non-Indigenous people with a vast array of community services, including activities for youth and Elders in areas such as health, education, human rights, culture and recreation. The focus of this study was on the recreation activities of the Centre. VAFCS' recreation department aims to "provide the urban aboriginal community a safe and positive space to participate in sport and recreation activities” (SFU 2012). The Centre's recreation programs are "designed to meet the physical, educational and cultural needs of the community by offering a multitude of programs indiscriminate of age, sex, status, income or (dis)ability” (VAFCS 2014). In addition, VAFCS contends that, "sport 
and recreation activities have the power to transform people into healthy, happy and expressive individuals; adding tremendous value to the community as a whole” (VAFCS 2014). The recreation program is funded by Nike and also receives support from federal and provincial governments (Infrastructure Canada 2009).

The recreation program provides both Indigenous and non-Indigenous peoples with opportunities to be immersed in cultural, social, and physical activities, such as pow wow dancing, hip-hop, archery, and "West coast nights" where families and friends gather over food and engage in cultural activities. The recreation department also facilitates involvement in competitive sports, with a particular focus on basketball and soccer at elite levels for Aboriginal peoples of all ages, including training youth for competitions such as the All Native Basketball Tournament. Throughout the summer months, VAFCS runs a day camp for (mostly) Indigenous children in the Greater Vancouver Area. It provides opportunities for summer employment for Indigenous youth while completing their studies, thereby providing valuable work experience and free training in various sport-related activities, such as coaching clinics, referee training, first aid and food safety (SFU 2012). At the time of research, the recreation program also supported a "Because we are Girls Group” to focus on better engaging young Indigenous women and girls in VAFCS’ activities, particularly those focused on recreation (also see Hayhurst et al. 2015 for further research with this program).

\section{Role Models and Leaders Australia (RMLA), Girls Academies}

Established in 2010 as a “private-sector led” non-profit NGO, RMLA aims to “develop and empower Aboriginal girls through leadership, sport and education” (RMLA 2014). Specifically, the Girls’ Academy program, based in high schools across Western Australia (WA), the Northern 
Territory (NT) and New South Wales (NSW), focuses on Aboriginal young women and girls ages 12-18 who "experience poverty, sickness, misfortune or disconnectedness from their community" (RMLA 2014, para. 5). According to its program brochure, RMLA (2014) "believes Aboriginal women play a pivotal role in Australian Aboriginal families and communities, yet their needs are often overlooked." The ultimate goal of RMLA is "to create an environment within schools where the girls receive the support and programs needed to help them realize [sic] their full potential” (RMLA 2014, para. 6). The research took place in RMLA's Girls Academy program in Perth, WA. The Girls Academy program focuses on "making a real difference to the school and local communities” by recognizing that, for example, “young people at risk need intensive personal support to bring positive change to their lives,” (RMLA 2014, para. 3). The program is sponsored by transnational corporations, such as Nestlé and Barrick Gold, among others.

The majority of young Indigenous women who attend the Girls’ Academy in Perth are secondary school 'boarders' who attend Clontarf Aboriginal College from rural areas in WA and NT, though there are some 'day students.' The Girls Academy is therefore housed inside the College as part of the broader RMLA NGO. The young women participating in the RMLA program were mostly from WA and the NT, where ATSI Australians constitute 30\% of the total population.

The Academy's program complements the College's curriculum by ensuring that the girls "achieve the necessary skills for further education, training and employment, and at the same time have the opportunity to improve their sporting and life skills” (RMLA 2014). Though the Academy focuses on sports such as netball, fitness programs, cultural excursions, and sporting carnivals, the mainstay of the Academy is basketball. Indeed, like the basketball program at VAFCS, the sport was positioned as beneficial from a grassroots participation perspective, particularly for the opportunity to engage in healthy living practices and develop new relationships. 


\section{Ethical considerations and data generation}

Following ethical approval from the Universities of Wollongong and Ottawa and the relevant Indigenous community groups, research agreements were developed and signed by communities in each country. Initially, the suitability of the proposed research questions and approaches were discussed with, and altered by, research participants in both countries. The lead author (Hayhurst) was fully immersed in VAFCS activities throughout this research, participating in a wide array of activities including volunteering during family and nutrition and cooking nights, attending the Because We Are Girls youth group meetings and volunteering with the Summer Day Camp. In Australia, the research centered on the experiences of RMLA staff, corporate donor staff, and the Aboriginal young women participating in the Girls Academy program based in Perth. Hayhurst spent time at the Academy in the office, and she participated in and observed training practices for the girls' basketball team.

Field visits to communities took place in July and October 2012 (Vancouver, Canada) and in May 2013 (Perth, Australia). Semi-structured, in-depth interviews were conducted by the lead author with employees from corporate sponsors, the young Indigenous women and the relevant NGO staff members from each country (five interviews with Canadian staff and four with Australian staff). The focus of this chapter will be on interviews conducted with the NGO employees in order to provide valuable insights about the constructive and adverse aspects involved in managing Indigenous-focused SDP programs for young women. In Canada, three of the staff interviewed identified as Aboriginal and two as non-Aboriginal; and in Australia, one of the three staff interviewed identified as Aboriginal and two as non-Aboriginal. Pseudonyms have been used to protect the identities of the participants involved. 
Following the transcription of interviews, participants were emailed a copy of their interview for verification and feedback. Interviews were then analyzed using QSR Nvivo 10, a qualitative software analysis program, with emerging themes and stories confirmed with staff members.

Throughout this research, we attempted to adhere to the principles of OCAP (Ownership, Control, Access and Possession) (see Lavallee \& Howard 2011). For example, following ethical approval from the University of Ottawa, an advisory council was formed with community members that were mutually agreed upon by VAFCS. This advisory council was crucial for periodically reviewing research processes (e.g., identifying appropriate cultural protocols for engaging with urban Indigenous young people). Similar measures were used to ensure the research with RMLA was conducted in an ethical and responsible manner that resonated with Indigenous knowledge; however, maintaining a strong relationship based on trust and meaningful connections was difficult and challenging - issues that we intend to explore in more depth in future publications.

\section{Benefits of Program Participation}

Developing Leadership Skills, Building Strong Role Models and Extending Horizons

Staff from both organizations highlighted the importance of the programs for improving the leadership capabilities of young Indigenous women and girls, which they also suggested enhanced the girls' confidence. Often, participation in team sports such as basketball (the primary sport of focus for both VAFCS and RMLA) was associated with teaching Indigenous young women leadership skills - a quality which they might galvanize in their communities. One way of accomplishing this was through exposure to young women like themselves who were "preparing for university” and seeking higher education opportunities. For example, Jennifer, a non-Indigenous VAFCS staff member, pointed out how older Indigenous girls in the program acted as role models, 
lending advice and providing ideas for future educational and career aspirations for the younger generation of basketball players. Many of the young women in the VAFCS' program also received basketball scholarships to play at prestigious colleges in the United States, which Jennifer argued gave the younger girls a goal to strive for that they might have otherwise missed.

Similar goals of building confidence and leadership were accomplished at RMLA through the young women's experiences of success through sport and more specifically through participating in public speaking as a tool to gain the skills to become positive role models and leaders for their communities. For example, RMLA was involved in hosting/hosted an “international women’s day breakfast,” which the RMLA program participants attended as volunteers. George described how one young Indigenous woman was selected to introduce the various delegates, including the Australian Prime Minister, in front of an audience of 1500 attendees who were invited to participate in the event. As part of its commitment to expanding their horizons, the RMLA program also provided important opportunities for the young women to travel to and from tournaments across Australia and abroad. For example, at the time of research, the girls were about to attend a tournament in China. Such opportunities exposed the young women to unique (international) opportunities, making their families and communities proud of their accomplishments.

At the same time, although the RMLA program aimed to promote, value, and instill leadership through its initiatives (both on and off the basketball court), often these young women's communities did not necessarily value such leadership attributes. As a result, the program's focus on building leadership, according to staff members, resulted in a struggle for the young women, particularly upon returning to their home communities. We further discuss these tensions in the latter half of the chapter. 
Building and Strengthening Social Ties with Communities and Other Indigenous Young Women Staff from both RMLA and VAFCS stressed how gender-focused Indigenous SDP initiatives were useful for building community and for strengthening social ties between young Indigenous women in the urban areas where each SDP initiative was located. For instance, Jennifer described the young women who participated in basketball at VAFCS as being "like sisters" who were able to support one another during difficult times and life challenges. In the passage below, she describes how one young women involved in VAFCS' programs used the support of her teammates to get through a difficult time:

It's a big community and what a community is supposed to be, so if they didn't have that connection, [one young woman] in particular, I'm pretty sure [this young woman] would have gone off the deep end if she didn't have some of those girls to really be there for her (Jennifer, interview, 17 July, 2012).

Social ties and bonds were also fostered and strengthened through activities such as community fundraising events and large basketball tournaments housed at the gym in VAFCS. The urgent need to mobilize funding in support of the sport and recreation program often brought the young women, and their communities, even closer together (Ryan, non-Indigenous staff member, VAFCS).

For the VAFCS staff, the social ties formed through the SDP program seemed to extend beyond the physical space of the Centre, and into the families and surrounding communities of support. In contrast, although the RMLA staff also described how social ties and bonds were formed and strengthened through the program, their emphasis was on building solidarity and connections among the young women on and off the basketball court, particularly those residing 
away from their home communities and families. The distinction in the ways social ties and communities were built was possibly due to the differing contexts of the programs. Whereas many of the young women served by RMLA were boarding at Clontarf College in Perth, away from their home families and communities, most of whom were in the NT, those involved in VAFCS' initiatives lived with their families or guardians in the Downtown Eastside Vancouver community.

\section{Key Challenges of Program Participation}

Although the staff members who were interviewed from both programs were enthusiastic about the opportunities provided through the program, they were not uncritical, and certainly recognized how Aboriginal cultures, inequalities, and gender issues intersected with program motivations and intentions to present particular challenges for the young women, for themselves and for the programs.

Gender (In)equality, (Neo-)colonialism, and Aboriginal Culture in Urban Life

Employees from both VAFCS and RMLA explained how notions of gender inequality intersected with Aboriginal culture, colonialism and perceptions of 'womanhood' to create a complex web of struggles for staff and young Indigenous women participants in both countries. This was particularly evident in the context of the urban environment, which staff suggested created tensions in terms of negotiating young Indigenous women’s ‘traditional’ (often associated with rural living) roles with their 'modern' (perceived as urban) ones. For example, some of the VAFCS’ staff (Ariel, Jennifer) argued that the important role of women in Indigenous societies on the West Coast was potentially 
eroded in the urban environment. For instance, Jennifer (interview, 17 July, 2012), an Indigenous woman, contended that:

These are our women, these are our life givers, these are our foundation and they need to be more - they need to be bigger. Here [in Vancouver], our societies are matriarchal and our women are starting to get quieter. I want them louder and rowdier!

Like the Canadian staff, the Australian interviewees referred to the ways that women in Indigenous cultures tend to be viewed as the foundation of their communities. As George (a non-Indigenous staff member) noted,

Indigenous women play a fundamental role in the communities ...if you like, they are the glue or the cornerstone of the healthy families. So if we don't have healthy - you know - well-developed women, then families will struggle. You could probably say the same about most cultures (interview, 18 July, 2012).

Some VAFCS staff also suggested that there were particular (traditional) ways Indigenous women are "supposed to act,” emphasizing that such characteristics did not necessarily correspond with participating in sport and recreation. They pointed out how multiple responsibilities, such as work and child care, and constraints, such as time and transportation, constantly served as barriers to young women’s involvement in VAFCS' sport and recreation programming. Though these gender stereotypes are certainly not unique to the Indigenous context, they serve as a palpable reminder of how the perceived characteristics and stereotypes of Indigenous culture, youth and gender (in)equality intersected to create particular discourses around inclusion and exclusion when it came to the (assumed) ways sport was taken up by the girls as a tool for their 'development.' 
At the same time, VAFCS’ recreation program attempted to explicitly align with, and incorporate, Indigenous cultural teachings into its curriculum. For example, Ariel (a nonIndigenous staff member) explained how the Because we are Girls group at VAFCS tried to connect Aboriginal culture with recreational pursuits:

We [the Because we are Girls group] try to bring out the uniqueness of Aboriginal females versus even non-white ...to not feel like you have to fit in but really let's celebrate where we come from, and let’s highlight the differences and lets understand why we may feel different than the other girls growing up ... There's a lot of teachings for young girls from the spirit world and from the Elders and from the individual clans as well and that's something that we bring in. They are trying to get the girls to understand specifically where they're coming from too, because some of their own realities might be very different versus [that of] their parents (interview, July 16, 2015). Certainly, colonialism, age and gender seemed to intersect to create significant challenges for the participation of young Indigenous women, particularly in the more competitive aspects of the sport and recreation program. For instance, the following quote from Brett (non-Indigenous staff member) illustrates how colonialism and contemporary expressions of sport intersect: The goal of our program is to encourage girls to participate and to feel comfortable in participating in sport...But sometimes what happens is when Aboriginal people get involved with mainstream sporting events or sport sometimes it’s not always the best case situation for them, because they experience some racism at times ... I think when you look back at the history of what we call it - Canada now - the biggest effect that this had on Aboriginal people was colonization (interview, July 18, 2015). 
At another point in this interview, Brett also suggested how sport can provide a platform for educating young Indigenous women and girls about colonialism, particularly in terms of how (neo-)colonial forces such as neoliberalism and patriarchy might shape their sporting experiences.

Besides cultural differences, socio-economic constraints clearly impacted the capacity of the young women to participate in the VAFCS program. For example, all five VAFCS staff members' pointed to childcare as a major barrier to the benefits of SDP. Indeed, as Ryan pointed out, socio-economic constraints, when connected to lack of time and childcare, meant that "if they're a single mother and they don't have other support, their priorities are different. It's hard to put, you know, coming and playing basketball as a priority over looking after your child” (interview, July 18, 2015). Though VAFCS was committed to keeping daycare fees below the citywide average, Jennifer noted there was no 'drop-in’ service available, meaning that even if daycare was affordable, accessing this service was challenging for those who were unable to plan ahead for a variety of reasons.

For the RMLA staff, many of the issues were associated with the challenges for young women from rural and remote environment being expected to engage with urban values and priorities. For example, as Robin (Indigenous, RMLA staff member) suggested, it was difficult for the young women to appreciate the type of sports being promoted through the program due to the young women's disconnection with their urban surroundings. As she explained: "Some of the girls from remote communities don't even like playing sports that much or they're always sitting out doing something else, or they're always even wagging [missing] classes cause they just don’t get the work” (interview, 13 May, 2013). 
Like VAFCS, RMLA used sport as a tool to encourage young women to better prepare for employment, arguing that, by obtaining an income and a secure job, their lives would improve significantly. This was often done through corporate sponsorships. For instance, Nestlé provided employment training opportunities, whereby RMLA participants would travel to the Nestlé headquarters in Sydney to obtain training in marketing, human resource management and/or public relations. The Nestlé initiative also included hiring the RMLA Clontarf girls to be involved in merchandising, by testing out products with 'key markets' (e.g., Aboriginal youth). As George (non-Aboriginal, staff member, RMLA) testified, “there’s nothing more powerful than seeing bright young Indigenous women in the work place;” however, George also acknowledged that it was increasingly difficult for the girls to find secure employment opportunities, as upon graduating in year twelve many of them ( $90 \%$, he estimated) returned to their home communities, where few career prospects were available, despite their qualifications working for Nestlé (interview, 16 May, 2013).

Robin, however, suggested that the corporate sponsorship and involvement provided the young women with the opportunity to address challenges and gain experience in the 'life world' to which they would perhaps not otherwise have been exposed:

The advantages [of corporate sponsors] are they're [the Indigenous young women] getting noticed and we are as well as a program. It’s really good to actually get people [corporate sponsors] on board just so we can get our girls out there and get the feel of the life world and what can really happen for them (interview, 13 May, 2015). While these opportunities for employment were potentially beneficial, through offering the young women a source of income and work experience, as we further discuss below, it seems possible based on our findings that the life world that Robin refers did not necessarily 
correspond to the cultural values, realities, and priorities of the Indigenous young women in the RMLA program.

\section{Discussion}

Our findings have demonstrated both beneficial and challenging aspects of gender-focused, Indigenous SDP programs in Canada and Australia. The staff who were interviewed for the study argued that these initiatives were beneficial for a number of purposes: developing leadership skills; learning from and creating, strong young Indigenous role models; building strong social ties of support; fostering confidence; and exposing young Indigenous women to educational and employment opportunities. At the same time, interviewees also highlighted the challenges in conducting gender-focused SDP programs for Indigenous young women in urban environments and described the challenging contexts that influenced the success of these initiatives, and the experiences and outcomes for the young women who were the intended beneficiaries. Our postcolonial feminist, intersectional approach revealed how gender inequalities, (neo-)colonialism and Indigenous culture made the involvement of Indigenous young women and girls in these programs difficult and the outcomes sometimes different from those intended. In particular, these challenges were evident through issues such as cultural difference, patriarchy and poverty.

What we have demonstrated in the context of SDP in the Global North is how sport's ties to neoliberalism, in this case through corporate sponsorships, produce particular effects. SDP initiatives may potentially reproduce the hegemony of neoliberalism by striving to teach these young women to participate in competitive capitalism (see Darnell \& Hayhurst 2013). We do, however, understand that learning to participate in competitive capitalism may be a necessary reality for survival in the current Canadian and Australian political-economic climates, particularly because the 
benefits of these programs as revealed in this research - such as improved leadership, team work, social support and confidence - are important skills and qualities that seem to possess positive aspects for Indigenous young women. What may be more useful, however, is for SDP programs to forge connections with movements such as Idle No More. Indeed, building solidarity among Indigenous young women in Canada and Australia vis-à-vis an activist-oriented SDP program would be potentially interesting for creating a "common context of struggles against specific exploitative structures and systems” (Mohanty 2003, p. 49) that could foster alliances among Indigenous young women across borders. Along these lines, it is imperative that SDP scholars and practitioners in the Global North who seek to support, fund, and implement SDP recognize that similar sport-focused development initiatives are occurring in their own countries (e.g., Canada and Australia), particularly as "uncovering Indigenous struggles are useful resources for theorizing convincing alternatives to neoliberalism” (Choudry 2010, p. 101). As Choudry (2010) further contended

The sense of betrayal, loss of sovereignty and despair felt among many non-Indigenous people affected by free market capitalism also provides a window of opportunity to build solidarity with Indigenous peoples... But the tendency of many organizations [NGOs] to only support Indigenous peoples’ struggles during visible crises poses a challenge to building broader anti-colonial critiques and long-term alliances, either locally or internationally. (pp. 100-101)

Such an approach - that is, one that challenges colonialism and capitalism - is in stark contrast to approaches where, in this window of opportunity, corporations see the chance to use structural inequalities and their consequences for their own benefits, such as to build a workforce of young women with the leadership characteristics that they deem to be desirable. 
What may appear on the one hand to be corporate philanthropy, attempts at corporate social responsibility or even supporting Indigenous peoples in their struggles, can be seen on the other hand as reinforcing the colonial, patriarchal project by failing to address broader and intersecting issues in both Canada and Australia.

\section{Conclusion}

An Indigenous led, activist approach to SDP for girls and young women in Indigenous communities could result in vast changes in the SDP landscape. An approach that focuses on building leadership skills that are consistent with Indigenous approaches to leadership, and emphasizes uniting young Indigenous women in fighting the colonial and capitalistic forces that have resulted in their marginalization could prove particularly effective. The paradox is, however, that the conditions that enable multinational corporations to invest in SDP programs for Indigenous peoples are the very ones that result in the difficulty that Indigenous peoples would very likely experience in building their own programs. While many programs purport to work in "partnerships" in SDP programs, it is often difficult to get beyond the mere rhetoric of partnerships and to address power imbalances between donors and recipients (Hayhurst \& Frisby 2010; Nicholls, Giles \& Sethna 2010). As such, and in order to respond to the barriers that continue to hamper SDP efforts with Indigenous communities, it is important to ensure that SDP practitioners and movement organizers reflect on embedded values and approaches, recognize cultural specificity and move to a supportive, collaborative form of engagement with Indigenous defined and led SDP activity.

Future research in this area might further explore the ways that urban Indigenousfocused SDP programs deliver 'employment pedagogies' - that is, teaching young Indigenous 
women (and Indigenous youth more broadly) employment skills through SDP interventions. How are these skills taught, taken up and utilized? What are the (unintended) effects of the focus on employability vis-à-vis SDP programs that target Indigenous young women? A second - and broader - avenue of future study might be to further examine the utility of comparative approaches to SDP interventions in the Global South and North. How do these approaches contribute to policy dialogues and program learning? Finally, the ways in which corporate funded SDP initiatives affect - if at all - Aboriginal community members' views of the multinational corporations that fund these programs would make a strong contribution to understanding the ways in which corporations are able to leverage their sponsorship for gains in other areas (e.g., access to land for exploration, an untapped market of consumers, etc).

\section{References}

Australian Human Rights Commission 2008, A statistical overview of Aboriginal and Torres Strait Islander peoples in Australia, Australian Human Rights Commission, 17 September 2015, $<$ https://www.humanrights.gov.au/publications/statistical-overview-aboriginal-and-torres-strait- 
islander-peoples-australia-social>.

Cho, S, Crenshaw, KW \& McCall, L 2013, 'Toward a field of intersectionality studies: Theory, applications, and praxis’, Signs, vol. 38, no. 4, pp. 785-810.

Choudry, A 2010, ‘What’s left? Canada’s “global justice” movement and colonial amnesia’, Race \& Class, vol. 52, no. 1, pp. 97-102.

Coleby, J \& Giles, AR 2013. 'Discourses at work in media reports on Right To Play’s “Promoting Life-Skills in Aboriginal Youth” program’, Journal of Sport for Development, vol. 1, no. 2, pp. $1-14$.

Davis, K 2008, 'Intersectionality as buzzword: A sociology of science perspective on what makes feminist theory successful', Feminist Theory, vol. 9, no. 1, pp. 67-85.

Darnell, SC \& Hayhurst, L 2013, 'De-colonizing the politics and practice for sport-for-development: Critical insights from post-colonial feminist theory and methods', in N Schulenkorf \& D Adair (eds.), Global sport-for-development: Critical perspectives, Palgrave Macmillan, New York, pp. 33-61.

de Finney, S 2010, “’We just don’t know each other”: Racialised girls negotiate mediated multiculturalism in a less diverse Canadian city’, Journal of Intercultural Studies, vol. 31, no. 5, pp. 471-487.

Environics Institute 2011, Urban Aboriginal peoples’ study: Vancouver report, Toronto, ON: Author. Galipeau, M \& Giles, AR 2014, ‘An examination of cross-cultural mentorship in Alberta’s Future Leaders Program’, in K Young \& C Okada (eds.), Research in the sociology of sport, Emerald, Bingley, UK, pp. 147-170.

Government of Western Australia 2014, Aboriginal sports program, Government of Western Australia, 17 September 2014, < http://www.dsr.wa.gov.au/aboriginal>. 
Harris, A 2004, Future girl: Young women in the twenty-first century, Routledge, London.

Hayhurst , LMC 2011a, ‘Corporatising sport, gender and development: Postcolonial IR feminisms, transnational private governance and global corporate social engagement, Third World Quarterly, vol. 32, no. 3, pp. 531-549.

Hayhurst, LMC 2011b, The corporatization of sport, gender and development: Postcolonial IR feminisms, transnational private governance and global corporate social engagement, Munk School of Global Affairs Working Paper Series 2009-10, viewed, $<$ http://papers.ssrn.com/sol3/papers.cfm?abstract_id=1942740>

Hayhurst, LMC \& Frisby, W 2010, 'Inevitable tensions: Swiss and Canadian sport for development NGO perspectives on partnerships with high performance sport', European Sport Management Quarterly, vol. 10, no. 1, pp. 75-96.

Hayhurst, LMC \& Giles, AR 2013, 'Private and moral authority, self-determination, and the domestic transfer objective: Foundations for understanding sport for development and peace in Aboriginal communities in Canada, Sociology of Sport Journal, vol. 30, no. 4, pp. 504-519. Hayhurst, LMC, Giles, AR, Radforth, WM, and The Vancouver Aboriginal Friendship Centre Society 2015, '”I want to come here to prove them wrong”: Using a post-colonial feminist participatory action research (PFPAR) approach to studying sport, gender and development programmes for urban Indigenous young women', Sport in Society, online first, pp. 1-16.

Idle No More n.d. The vision, Idle No More, 13 July 2014, <http://www.idlenomore.ca/vision>. Infrastructure Canada 2009, Governments announce support for Vancouver Native Housing Society and Vancouver Aboriginal Friendship Centre Society, Infrastructure Canada, Vancouver, BC, viewed 9 June 2014, < http://www.infrastructure.gc.ca/media/newsnouvelles/2009/20091023vancouver2-eng.html> . 
Kidd, B 2008, 'A new social movement: Sport for development and peace, Sport in Society, vol. 11, no. 4, pp. 370-380.

Killon, S \& Magnus, P 2010, Australia’s health 2010, Australian Institute of Health and Welfare, Canberra, 13 September 2014, http://www.aihw.gov.au/WorkArea/DownloadAsset.aspx?id=6442452962.

Lavallee, LF \& Howard, HA 2011, Urban Aboriginal diabetes research project report, Anishnawbe Health Toronto, Toronto, ON, 16 July 2014, < http://www.aht.ca/images/stories/NEWSRESOURCES/RESEARCH/Urban\%20Aboriginal\%20Diabetes\%20Research\%20Project\%20R eport.pdf $>$.

MacDonald, D, Abbott, R \& Jenkins, D 2012, 'Physical activity of remote Indigenous Australian women: A postcolonial analysis of lifestyle’, Leisure Sciences, vol. 34, no. 1, pp. 39-54.

Marchand, M 2009, ‘The future of gender and development after 9/11: Insights from postcolonial feminism and transnationalism’, Third World Quarerly, vol. 30, no. 5, pp. 921-935.

McEwan, C 2009, Postcolonialism and development, Routledge, New York.

McHugh, TLF, Coppola, AM \& Sinclair, S 2013, ‘An exploration of the meanings of sport to urban Aboriginal youth: A photovoice approach', Qualitative Research in Sport, Exercise and Health, vol. 5, no. 3, pp. 291-311.

Mohanty, CT 2003, Feminism without borders: Decolonizing theory, practicing solidarity, Duke University Press, Durham, NC.

Nelson, A 2009, 'Sport, physical activity and urban Indigenous young people’, Australian Aboriginal Studies, vol. 2, no. 2, pp. 101-111.

Nelson, A, Macdonald, D \& Abbott, R 2010, 'The cultural interface: theoretical and 'real' spaces for urban Indigenous young people and physical activity’, in J Wright \& D Macdonald (eds.), 
Young people physical activity and the everyday, Routledge, London, pp. 75-92.

Nicholls, S, Giles, AR, \& Sethna, C 2011, 'Perpetuating the 'lack of evidence' discourse in sport for development: Privileged voices, unheard stories and subjugated knowledge’, International Review for the Sociology of Sport, vol. 46, pp. 249-264.

Place J 2012, The health of Aboriginal people residing in urban areas, National Collaborating Centre for Aboriginal Health, Prince George, BC, 14 August 2014 , <http://www.nccahccnsa.ca/Publications/Lists/Publications/Attachments/53/Urban_Aboriginal_Health_EN_web.p $\mathrm{df}>$.

Right To Play 2014, Promoting life-skills in Aboriginal youth (PLAY) program, Right to Play, 14 August 2014, < http://www.righttoplay.ca/Learn/ourstory/Pages/PLAY-Program.aspx\#>

RMLA 2014, Values, Role Models and Leaders Australia, 26 April 2014, $<$ http://www.rolemodelsaustralia.com/values.php?id=47> .

Rose, A \& Giles, AR 2007, ‘Alberta’s Future Leaders Program: A case study of Aboriginal youth and community development', Canadian Journal of Native Studies, vol. 27, no. 2, pp. 421-446.

Rousell, D \& Giles, AR 2012, 'Leadership, power and racism: Lifeguards’ influences on Aboriginal people’s experiences at a Northern Canadian aquatic facility', Leisure Studies, vol. 4, no. 31, pp. 409-428.

Rovito, A \& Giles, AR 2013, 'Youth development through recreation: Eurocentric influences and Aboriginal self-determination', in C Hallinan \& B Judd (eds.), Native games: Indigenous peoples and sports in the post-colonial world, Emerald, Bingley, UK, pp. 183-203.

Rossi, T \& Rynne, SB 2013, The sport demonstration project: An evaluation, Australian Sports Commission. 
Rossi, A, Rynne, S \& Nelson, A 2013, 'Doing whitefella research in blackfella communities in Australia: Decolonizing method in sports related research’, Quest, vol. 65, no. 1, pp. 116-131. Rynne, S \& Rossi, T 2012, The impact of Indigenous community sports programs: The case of surfing, Australian Sports Commission, Canberra.

Simon Fraser University 2012, Vancouver Aboriginal Friendship Centre, Simon Fraser University, 20 September 2014, http://www.sfu.ca/olc/stories/topic/vancouver-aboriginal-friendship-centre. Statistics Canada 2008, Aboriginal peoples in Canada in 2006: Inuit, Métis and First Nations, 2006 Census, Minster of Industry, Ottawa, ON, 14 June 2014, < http://www12.statcan.ca/censusrecensement/2006/as-sa/97-558/pdf/97-558-XIE2006001.pdf>.

Talaga, T 2012, 'First Nations Right to Play moves into 39 First Nations’, Toronto Star, 9 February 2012, 14 September 2014, <http://www.thestar.com/news/ontario/2012/02/09/first_nations_right_to_play_moves_into_39 _first_nations.html>.

Tatz, C 1994, Aborigines: Sport, survival and violence, Criminology Research Council, 14 September 2015, <http://www.criminologyresearchcouncil.gov.au/reports/18-98.pdf>.

VAFCS 2014, Recreation, 21 September 2014, <http://www.vafcs.org/programs/recreation/>. Zubrick SR, Lawrence DM, Silburn SR, Blair E, Milroy H, Wilkes T, Eades S, D’Antoine H, Read A, Ishiguchi P, \& Doyle S 2004, The Western Australian Aboriginal child health survey: The health of Aboriginal children and young people, Telethon Institute for Child Health Research, Perth, 22 September 2014, <http://aboriginal.telethonkids.org.au/media/393443/western_australian_aboriginal_child_healt h_survey_citations.pdf $>$. 